\title{
Ricardo Palma y Manuel González Prada: Historia de una Enemistad
}

El choque que ocurre entre Palma y Prada en el Perú, no es el mero resultado de accidentes políticos ni tampoco una rencilla personal por laureles literarios. El de ellos es el choque dialéctico entre dos tendencias: ${ }^{1}$ tradición y renovación. Es el choque entre un conservador, romántico-a-sumanera y un modernista, mezcla de místico y político. Al mismo tiempo es el encuentro violento entre dos generaciones y dos épocas. Dicho fenómeno lo veremos repetido en muchos países de América, mas para el caso peruano es el primero que se presenta con tanta nitidez y energía.

Ricardo Palma (1833-1919) es el escritor laureado e internacionalmente conocido; González Prada (1848-1918), en cambio, es un nombre nuevo en el mundo de las letras. Palma es miembro prominente del Club Literario -institución oficialista que agrupa a los románticos y sus compañeros de ruta-; Prada es el centro del Círculo Literario - grupo opositor del Club, surgido después de la Guerra del Pacífico ${ }^{2}$ y llamado a convertirse, años más tarde, en la Unión Nacional, frustrado primer intento de un Partido Radical peruano-.

En su "Conferencia en el Ateneo de Lima", González Prada lanza su primer dardo contra Palma:3

1 Se usa la palabra tradición como sinónimo de una tendencia conservadora tanto en términos políticos como literarios. Al mismo tiempo, renovación quiere significar una tendencia innovadora mas no revolucionaria.

2 Se conoce con este nombre a la guerra entre el Perú y Chile (1879), suceso que culminó con la derrota del primer país y la ocupación de su rritorio.

Este hecho es de singular importancia en la vida y obra de González Prada y su generación.

3 Se ha respetado la peculiar ortografia del autor. 
Quien escribe hoi i desea vivir mañana, debe pertenecer al día, a la hora, al momento en que maneja la pluma. Si un autor sale de su tiempo, ha de ser par'adivinar las cosas futuras, no para desenterrar ideas i palabras muertas.

Arcaismo implica retroceso: a escritor arcaico, pensador retrógrado. ${ }^{4}$

Definitivamente, estas palabras de 1886 van dirigidas a criticar la búsqueda en el pasado que realizara Palma en sus Tradiciones Peruanas El escritor, dice Prada, si sale de su tiempo, debe hacerlo para conver. tirse en un "futurista" y no en un "pasadista".

No hay constancia de que don Ricardo Palma reaccionara ante este primer ataque. $Y$ habrá de esperar hasta el 28 de julio de 1888 para recibir un segundo golpe: el "Discurso en el Politeama". ${ }^{5}$ En esta pro. clama revanchista, de un indigenismo incipiente, antiespañola y positivis. ta, también se da tiempo Prada para atacar acremente a la generación responsable de la derrota frente a Chile:

En esta obra de reconstitución i venganza no contemos con los hombres del pasado: los troncos añosos i carcomidos produjeron ya sus flores de aroma delteréreo $i$ sus frutas de sabor amargo. ¿Que vengan árboles nuevos a dar flores nuevas i frutas nuevas! ¡Los viejos a la tumba, los jóvenes a la obra!

Este grito pedía obviamente un tompimiento no sólo con los políticos improvisados e irresponsables del pasado sino con todo lo que con ese pasado se identificara, incluyendo los escritores. A este respecto, Luis Alberto Sánchez nos dice: " $Y$ desde ese entonces se dividió el campo intelectual peruano entre los admiradores del virreinato y la vocación galana, como don Ricardo, y los partidarios de las nuevas ideas, antiespañoles, anticolonialistas, antiacadémicos y antilimeños, como Prada". ${ }^{7}$

Palma, que al parecer asistió a la festividad del Politeama, debió comprender entonces que había llegado el momento de enfrentarse a la crítica de la nueva generación.

4 Manuel González Prada, Pájinas libres, (Lima: Editorial Thesis, S. A., 1966), p. 19.

5 Discurso leído en el teatro Politeana de Lima con motivo de una velada patriótica organizada con el fin de recolectar fondos para el rescate de Tacna y Arica, provincias peruanas en poder de Chile.

6 Manuel González Prada, op. cit., p. 51.

7 Luis Alberto Sánchez, La literatura pertana, Tomo VI, (Asunción del Paraguay: Editorial Guarania, 1951), p. 62. 
El 30 de octubre de 1888, en el "Discurso en el teatro Olimpo", Prada se lanza a un ataque más directo y enconado:

Cultivamos una literatura de transición, vacilaciones, tanteos i luces crepusculates. De la poesía van desapareciendo las descoloridas imitaciones de Bécquer; pero en la prosa reina siempre la mala tradición, ese monstruo enjendrado por las falsificaciones agridulcetes de la historia i la caricatura microscópica de la novela. ${ }^{8}$

Usa la palabra "tradición" para referirse al géneto cultivado por Palma y sus imitadores. $\mathrm{Y}$ va aún más lejos cuando en el párrafo siguiente desconoce totalmente el relativo renombre internacional del tradicionista y tacha su obra de arcaica, refranera, grandilocuente y vacía de ideas:

El Perú no cuenta hoi con un literato que por el caudal i atrevimiento de sus ideas se levante a'laltura de los escritores europeos, ni que en el estilo se liberte de la imitación seudo purista o del romanticismo trasnochado. Hai gala de arcaismos, lujo de refranes i hasta choque de palabras grandilocuentes; pero, ¿dónde brotan las ideas? Se oye ruido de muchas alas, mas no se mira volar el águila. 9

Y más adelante, en las páginas finales del discurso, tidiculiza el estilo de Palma y vuelve a insistir en el carácter anacrónico de su obra:

Verdad en estilo i lenguaje vale tanto como verdad en el fondo. Hablar hoi con idiotismos i vocablos de otros siglos, significa mentir, falsificar el idioma. Como las palabras espresan ideas, tienen su medio propio en que nacen $i$ viven; injerir en un escrito moderno una frase anticuada, equivale a incrustar en la frente de un vivo el ojo cristalizado de una momia. ${ }^{10}$

Aquí ya reacciona don Ricardo y a pesar de su intento de hacerlo anónimamente, sale a la luz que es él quien publica en el diario "El Co. mercio" el artículo "Propaganda de la difamación". Dicha publicación -aparecida el 3 de noviembre de 1888 - acusa a Prada de haber difa. mado al pocta peruano Ricardo Rossell (1841-1909) en su "Discurso en el teatro Olimpo". Don Manuel responde diciendo que él no ha men-

8 Manuel González Prada, op. cit., p. 32.

9 Ibidem.

10 Manuel González Prada, op. cit., p. 37. 
cionado nombres propios en su discurso y que además el poeta Rossell es amigo suyo.

Descubierta su artimaña de querer enfrentar a Prada con Rossell, Pal. ma, el escritor por todos respetado queda en ridículo y como blanco seguro a los ataques de la nueva generación. Ya ha comprendido que su ciclo ha terminado y algo de esto deja ver en los títulos de sus tradiciones publicadas a partir del año 89: "Ropa vieja", que aparece en cse mismo año y "Ropa apolillada" (1891), pueden servir de ilustración.

Luego de varios años de relativa calma -especialmente debida al viaje de Prada a Europa - nuestras dos personalidades vuelven a encontrarse en 1912. En marzo de dicho año, siguiendo a un altercado con el gobierno de Augusto B. Leguía, Palma renuncia a su cargo de Director de la Biblioteca Nacional. A pesar de los esfuerzos de un grupo de simpatizantes que tratan de evitar que ningún posible candidato acepte el cargo, don Manuel desoye la petición y es nombrado nuevo Director. Un movimiento de adhesión le tinde homenaje a Palma en el teatro Municipal y un sinnúmero de acusaciones recaen sobre González Prada por haber acep. tado un puesto público.

Prada responde con la publicación de su Nota informativa acerca de la Biblioteca Nacional. ${ }^{11}$ En ella, so pretexto de informar al gobierno sobre el estado de la institución, acusa a la dirección de $\mathrm{Palma}^{12}$ de no haber llevado libros de contabilidad, de dejar el lugar en una situación caótica, de no haber catalogado, fichado ni encuadernado como hubiese correspondido y de haber sellado los libros y manuscritos con el nombre del Director. Además, le acusa de haber hecho anotaciones y comentarios personales en los libros de la Biblioteca. Y lleva esta última acusación hasta un extremo inaudito: le envía a Rufino Blanco Fombona un libro suyo que al parecer había sido anotado por el tradicionista.

Blanco Fombona, herido por las supuestas críticas de don Ricardo, le contesta en términos acres y ofensivos en el prólogo que le escribiera a la segunda edición de Pájinas libres (Madrid, 1915): en un pie de página, Fombona se pregunta por qué Palma, en sus Tradiciones perua. nas, se ha ensañado contra la memoria de Bolivar. Respondiendo a esto, dice que un limeño amigo suyo le ha referido una historia:

11 (Lima: Imprenta - Arica 358, 1912).

12 Es preciso mencionar aquí que, a pesar de las acusaciones de Manuel González Prada, el trabajo realizado por el "bibliotecatio mendigo", como se le llamó a Ricardo Palma, fue de suma importancia. Con la ocupación chilena, la Biblioteca Nacional había sido saqueada, terminando muchos de los libros y manuscritos en manos privadas o en las bibliotecas del país invasor. "La tarea del tradicionista al frente de la Biblioteca, reinaugurada el 28 de julio de 1884, fue senzillamente admirable" (Luis Alberto Sánchez, La literatura peruana, Tomo VI, Asunción del Paraguay: Editorial Guarania, 1951, p. 60). 
Algunos de los negros que llegaron entre las huestes de Bolívar, equivocados en el sentido de la gesta emancipadora, realizaron una serie de desmanes en la Capital peruana; una de aquellas fechorías fue la viola. ción de unas "pobres y honestas mujeres". Y continúa:

De este pecado mortal desciende Ricardo Palma.

Así explica mi amigo del Perú el odio de Ricardo Palma a la memoria de Bolívar y de sus tropas.

Don Ricardo ha olvidado, hasta ahora, incluir entre sus Tradi. ciones peruanas esta amarga tradición de familia. No podemos echár. selo en cara.

Me alegro que el vicjo mulato de Lima pueda leer antes de morirse esta breve nota. Se la debía. No tanto por vindicar la memoria de Bolívar como para corresponder a las acotaciones que él puso, según parece, al margen de alguna obra mía en la Biblioteca Nacional del Perú. Donde las dan las toman, seor feolenco. ${ }^{13}$

III

Como se puede apreciar, la disputa entre el tradicionista y el Maes. tro - como llamaban a González Prada- se vuelve cada vez más personal. Lo que en un principio no es sino una crítica a la literatura y la política de la generación en el poder, se transforma poco a poco en el en. cuentro violento de estas dos personalidades. Así, por un tiempo, ese choque dialéctico del que hemos hablado se pierde de vista y no es sino hasta las generaciones siguientes en que esta misma problemática vuelve a cobrar actualidad y a ser planteada en forma más elaborada y definitiva.

Prada es la voz principal del período de reconstrucción de la post. guerta (Guerra del Pacífico), sin embargo, es un hombre que no pertenece a su generación sino a otra futura. Ya se ha dicho que con él comienza un nuevo periodo para el Perú, pero no es sino hasta José Car. los Mariátegui ${ }^{14}$ y Víctor Raúl Haya de la Torre ${ }^{15}$ en que este nuevo período se va a consolidar. Desde este punto de vista, la polémica tradición-renovación sobrevive a los protagonistas del suceso original. Muertos

13 Rufino Blanco Fombona, Crítica de la obra de González Prada, (Lima: Fondo de Cultura Popular, 1966), pp. 21-22.

14 José Carlos Mariátegui (1895-1930): sociólogo, político y crítico literario. Fundó la revista Amauta, un partido socialista y organizó la Confederación de Trabajadores del Perú.

15 Nació en 1895. Político y ensayista. Fundador del Partido Aprista Peruano: partido de orientación marxista en sus comienzos. 
don Ricardo y don Manuel desaparecen los nombres que personifican la problemática, pero a ellos les sobreviven las dos épocas que aún pugnan por una solución.

Por un lado la fidelidad a lo español - fuertemente disminuida a raíz de los sucesos del 2 de mayo de $1866-{ }^{16}$ y la añoranza de una época ya ida. Por otro lado la rebeldía ante el presente -el Perú de la postguerra- y el clamor por la revancha. Por un lado la re-creación de una prosa ya pretérita, por otro una prosa innovadora y violenta. Por un lado la conformidad con gobiernos clericalizantes y conservadores, por otro la lucha por un Estado laico y un país liberal. Por un lado apatía si no ig. norancia frente problema indígena, por otro indigenismo en ciernes y preocupación por el cambio social. Son estas dos épocas, estas dos mentalidades, las que se enfrenta con Palma y González Prada.

Sin duda, es la Guerra con Chile la coyuntura que violenta esta polémica. Son los resultados de ella los que transforman al poeta y solitario Prada en el político que nunca llega a ser. $Y$ es don Manuel el encargado de enjuiciar a la generación precedente en la figura descollante de don Ricardo Palma.

Bruno Podestá A.

University of Texas

16 Luego de un incidente baladi, la misión "científica" española, que visitaba el Oceano Pacifico, tomó posesión de las Islas Chincha y presentó un reclamo contra el gobierno del Perú. El 2 de mayo de 1866 atacó el puerto del Callao y culminó el incidente con la victoria de las fuerzas peruanas. 